\title{
Initial Experience and Results of Combined Treatment for Atrial Fibrillation: Catheter Ablation with High-Power Short Duration Ablation and Left Atrial Appendage Closure
}

Fabricio Vassallo ${ }^{1,2, *}$, Eduardo Serpa ${ }^{1,2}$, Betina Reseck Walker ${ }^{1,2}$, Lucas Luis Meigre $^{1}$, Hermes Carloni ${ }^{1,2}$, Aloyr Simões Jr. ${ }^{1,2}$, Christiano Cunha ${ }^{1,2}$, Flávia Pezzinn ${ }^{1}$, Karla Loureiro ${ }^{1}$, Dalton Amaral $^{1,2}$, Carlos Alexandre Lovatto ${ }^{1,2}$, Walter Duarte Batista Jr. ${ }^{1,2}$, Renato Serpa ${ }^{1,2}$

\section{ORCID IDs}

Vassallo F (D) https://orcid.org/0000-0003-3915-4309

Serpa E (D) https://orcid.org/0000-0002-5777-1266

Meigre LL (D) https://orcid.org/0000-0002-6301-0498

Carloni H (D) https://orcid.org/0000-0001-6725-9568

Simões Jr. A (D) https://orcid.org/0000-0002-5601-7165

\author{
Cunha C (D) https://orcid.org/0000-0002-3427-6617 \\ Pezzin F (D) https://orcid.org/0000-0003-4833-6307 \\ Amaral D (D) https://orcid.org/0000-0001-9145-710X \\ Lovatto CA (D) https://orcid.org/0000-0002-9225-2875 \\ Batista Jr WD (D) https://orcid.org/0000-0003-2212-9158
}

\begin{abstract}
Introduction: Long-term freedom from atrial fibrillation (AF) after catheter ablation and, consequently, the potential for stroke reduction remain unpredictable. Recently, left atrial appendage closure (LAAC) became an effective mechanical alternative to oral anticoagulation $(\mathrm{OAC})$ for stroke prevention in AF patients. Objective: This study aims to evaluate the feasibility and safety of combined treatment for AF with catheter ablation (CA) with the high-power short duration technique associated with LAAC in one single procedure. Methods: Patients with non-valvular AF who underwent combined CA and LAAC procedure were included in the retrospective observational study. Between April 2018 and October 2020, 13 patients with AF were included, eight (61,54\%) males, eight (61.54\%) with persistent AF (PersAF), mean age 68.54 (65-84) years old, mean time from AF diagnosis to treatment 13.08 (3-33) months, mean CHA2VASC2 5.08 (3-7), all patients with coronary or vascular disease, 12 (92.31\%) with hypertension, five (38.46\%) with left ventricular dysfunction, four (30.77\%) prior strokes using OAC and four (30.77\%) patients with diabetes. Indications for LAAC included history of contraindication to OAC because of severe bleeding in eight (61.54\%), previous stroke in four (30.77\%) and two (13.08\%) patients with LAA thrombus, despite the use of two different OAC (one associated with bleeding). One patient had a pseudoaneurysm in femoral artery, and two patients died of non-procedure complications after 30 days. At six months, angiotomography showed successful complete sealing of the LAA in seven (77.72\%) of nine patients evaluated, and the two patients without it had a leak of less than 2 mm. After mean
\end{abstract}

1. Instituto de Cardiologia do Espírito Santo - Vitória (ES) - Brazil.

2. Hospital Santa Rita de Cassia - Vitória (ES) - Brazil.

*Corresponding author: fabricio@arritmiaes.org

Received: Jan 13, 2021 | Accepted: Mar 24, 2021 
follow-up of 14 months (five to 33), 10 (90.91\%) of the 11 patients were in sinus rhythm. Three (27.27\%) patients, one in blanking period, recovered sinus rhythm after amiodarone. No cardioembolic or bleeding events occurred. Conclusion: In this small observational study, we showed the feasibility and safety of the combined therapy with AF catheter ablation with LAAC with a high rate of sinus rhythm and no cardioembolic event.

KEYWORDS: Atrial fibrillation; Catheter ablation; Left atrial appendage closure; Watchman device; Echocardiography transesophageal.

\section{INTRODUCTION}

Catheter ablation (CA) has emerged as a safe and effective treatment for atrial fibrillation (AF) and has a class I recommendation supported with level A evidence in current European Society of Cardiology (ESC) guidelines ${ }^{1}$, with success rates of $30-75 \%$ depending on the type of $\mathrm{AF}$ and comorbidities such as structural heart disease ${ }^{2}$. So far, no randomized prospective trials have shown significant reduction in thrombo-embolic events after CA. Due to this variety in the recurrence rate and the absence of controlled clinical trials, guidelines recommend indefinite continuation of nonvitamin $\mathrm{K}$ antagonist (VKA) oral anticoagulation [(N)OAC] therapy after $\mathrm{CA}$ for $\mathrm{AF}$ in patients at high risk of stroke, regardless of the rhythm outcome, based on a careful assessment of both stroke and bleeding risk ${ }^{1,3}$.

In patients with an increased bleeding risk or due to cardioembolic events despite the use of OAC, left atrial appendage closure (LAAC) by means of a mechanical device might provide an alternative to lifetime anticoagulation and its complications. Safety and efficacy of LAAC with the Watchman device have been shown in the large-scaled nonrandomized and randomized clinical trials $s^{4-6}$. Since both CA and LAAC require transseptal catheterization for left atrial access, combining both procedures in one single procedure may provide a straightforward strategy aiming at concomitant rhythm control as well as stroke prevention, without the additional risk of multiple procedures.

A small number of single-center case series have described combinations of the $\mathrm{CA}$ procedure and the percutaneous transcatheter $\mathrm{LAAC}^{7-11}$. Recently, multicenter registries ${ }^{12,13}$ reported excellent feasibility and safety of the combined procedure after acute and long-term follow-up.

\section{OBJECTIVE}

The aim of the study was to evaluate the feasibility and security of combined treatment for symptomatic and medication refractory AF with CA with the high-power short duration (HPSD) technique associated with LAAC in one-single procedure.

\section{METHODS}

We conducted this retrospective observational study with consecutives patients with non-valvular $\mathrm{AF}$ who underwent combined CA and LAAC procedure because of formal contraindications to long-term use of OAC or for those patients who had experienced cardioembolic events despite the regular use of it. Between April 2018 and October 2020,13 patients with $A F$ were included. Eight (61,54\%) of them were males, eight (61.54\%) had persistent AF (PersAF) and five (38.46\%) paroxysmal AF, the mean age was 68.54 (65-84) years old, and the mean time from AF diagnosis to treatment was 13.08 (from three to 33) months. Patients had a high mean $\mathrm{CHA}_{2} \mathrm{VASC}_{2}$ of 5.08 (3-7), all patients had coronary or carotid and/or peripheral vascular disease, 12 (92.31\%) hypertension, seven (53.85\%) obstructive sleep apnea disorders, seven (53.85\%) patients showed moderate and severe non-dialytic renal failure, five (38.46\%) left ventricular dysfunction, four (30.77\%) prior ischemic strokes events and four (30.77\%) presented diabetes (Table 1). 
Table 1. Clinical features of patients.

\begin{tabular}{lc}
\hline Clinical features & Patients \\
\hline Males & $8(61.54 \%)$ \\
Persistent AF & $8(61.54 \%)$ \\
Mean age (years old) & $68.54(65-84)$ \\
Mean time from diagnosis to ablation (months) & $13.08(3-33)$ \\
Mean CHADS,VASC & $5.08(3-7)$ \\
Coronary and/or vascular disease & $13(100 \%)$ \\
Arterial hypertension & $12(92.31 \%)$ \\
Obstructive sleep apnea & $7(53.85 \%)$ \\
Moderate/severe renal dysfunction & $7(53.85 \%)$ \\
Left ventricular dysfunction & $5(38.46 \%)$ \\
Prior ischemic strokes & $4(30.77 \%)$ \\
Diabetes mellitus & $4(30.77 \%)$ \\
\hline
\end{tabular}

AF: atrial fibrillation.

Indications for LAAC included history 8 (61.54\%), with formal contraindication to long-term use of OAC including non-VKA (in these cases, two drugs with different mechanism of action) and warfarin, because of significant bleeding. Previous strokes were seen in four (30.77\%) patients with regular use of NOAC, and in two (13.08\%)-one with also significant gastrointestinal bleeding (GIB)-with LAA thrombus, despite the use of two different NOAC (Table 2).

Table 2. Clinical indications for left atrial appendage closure.

\begin{tabular}{ll}
\hline Left atrial appendage closure indication & Patients $^{*}$ \\
\hline Severe bleeding & $8(61.54 \%)$ \\
Prior cardioembolic events & $4(30.77 \%)$ \\
Left atrial appendage thrombus using oral anticoagulants & $2(13.08 \%)$ \\
\hline
\end{tabular}

*The sum of the number of patients was more than $100 \%$ because one patient with severe bleeding had also an atrial appendage thrombus during use of oral anticoagulant.

\section{Pre-Ablation Investigation for Thrombus Exclusion}

For the most patients, 11 (84.62\%), angiotomography (Fig. 1) was the method of choice for thrombus exclusion and LAAC approach preparation. Because of a pre-dialysis renal failure status in two (15.38\%) patients, we could not use this method, and the protocol was changed to transesophageal echocardiography (TEE) (Fig. 2). Both methods were performed in no more than 48 hours before the CA and LAAC.

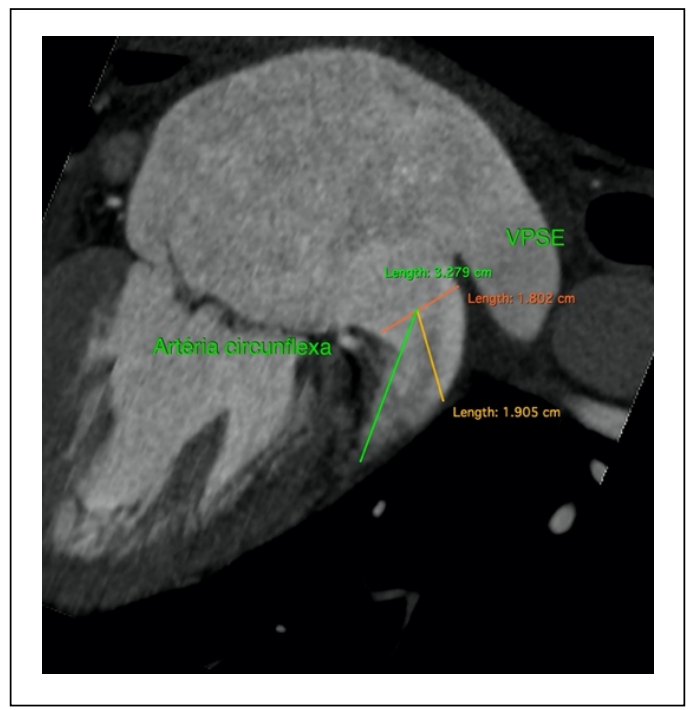

VPSE: left superior pulmanary vein; arteria circunflexa: left circumflex artery.

Figure 1. Angiotomography of left atrium and left atrial appendage before catheter ablation and left atrial appendage closure. 


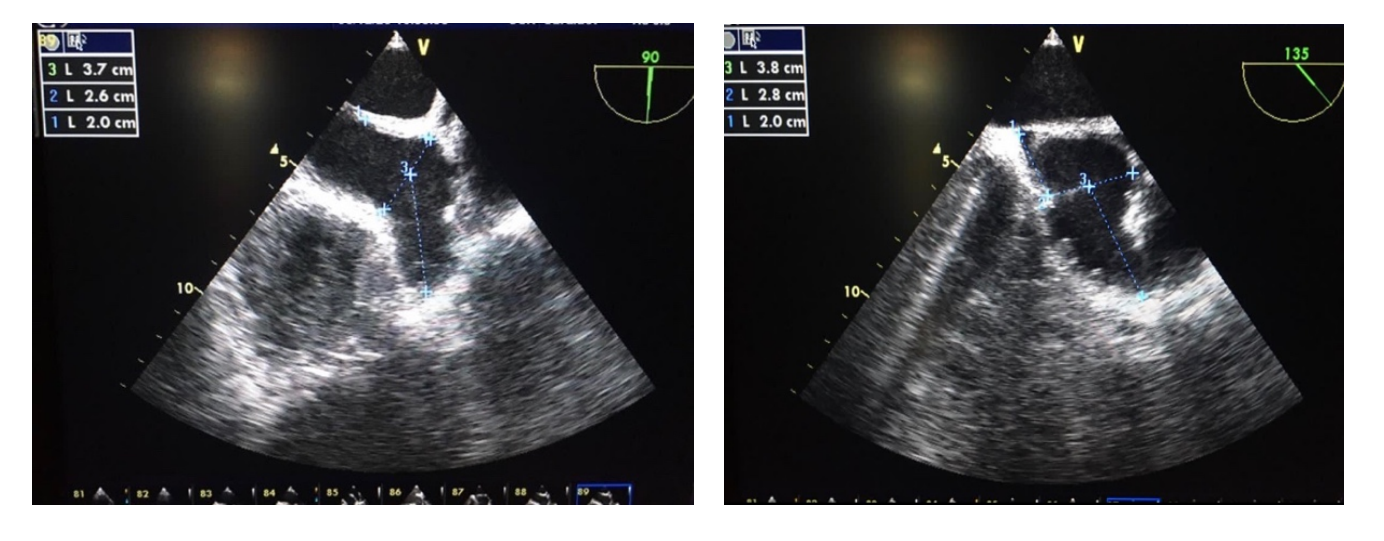

Figure 2. Echocardiography before catheter ablation and left atrial appendage closure from upper left to right bottom. The four projections for left atrial appendage measure in (A) 0, (B) 45, (C) 90 (D) and $135^{\circ}$.

\section{Catheter Ablation}

All the patients, except one, with contraindication to $\mathrm{OAC}$, underwent the catheter ablation without prior use of this medication and received a bolus of $5.000 \mathrm{IU}$ of heparin before and after transeptal puncture. The patient with severe GIB associated with left atrial appendage thrombus was treated with a half dose of apixaban associated with clopidogrel 60 during days prior to CA. All other patients underwent ablation with an uninterrupted OAC. All of them had their antiarrhythmic drugs suspended for 5 half-lives prior to the procedure, apart from amiodarone, that was maintained for the procedure.

Our aim was to isolate the antral portion of the pulmonary veins ${ }^{14,15}$. Patients with a previous diagnosis of atrial flutter also had this ablated, however at the end of the pulmonary vein isolation (PVI). The time of radiofrequency and additional time for ablation were excluded from the study analysis. Procedures were performed in sinus rhythm, and patients who were in atrial fibrillation or flutter underwent electrical cardioversion immediately before the ablation. At the end of the procedure, all of them were submitted to a challenge of $12 \mathrm{mg}$ of adenosine for each antrum of the pulmonary veins, in order to unmask dormant veins and to evaluate for re-ablation of their reconnection ${ }^{16,17}$.

In all patients, the Ensite Velocity 4.0 or 5.0 with mapping system was used with TactiCath ${ }^{\mathrm{TM}}$ contact force sensing catheter and the Agilis ${ }^{\mathrm{TM}}$ deflectable sheath. The Viewflex ${ }^{\mathrm{TM}}$ intracardiac echocardiography probe (St. Jude Medical, United States) and the Ampere ${ }^{\mathrm{TM}}$ radiofrequency generator (Abbott, United States) were used.In addition to the real-time contact force values in all radiofrequency applications, we followed the impedance measurements looking for gradual falls indicating lesion formation. We used a dragging technique for ablation and avoid catheter jumps, and, if this occurred, the radiofrequency application was immediately stopped, and we returned to the same location before the abrupt movement to continue the application ${ }^{18-22}$. Although available, we did not use other features provided by the contact force catheter like lesion index (LSI) and force-time integral (FTI) ${ }^{23}$.

All patients received esophageal temperature monitoring as described previously ${ }^{24}$. We used a power set to 45 watts for an average time of 6 to 8 seconds and 5 to $10 \mathrm{~g}$ of contact on the posterior wall of both sides and atrial roof. On the anterior wall, we programmed the power to 50 watts with an estimated pressure of 10 to $20 \mathrm{~g}$ for an average period of 6 to 8 seconds. The irrigation pump was programmed at $35 \mathrm{~mL} / \mathrm{min}$ regardless of power.

\section{Left Atrial Appendage Closure}

After CA completion, the transseptal AgilisTM was exchanged for the Watchman sheath. Watchman implantation was subsequently carried out under TEE guidance.

Procedural details on Watchman implantation have previously been described ${ }^{4}$. In brief, after determination of LAA anatomy and size, an appropriate device size was chosen from the five available sizes (21,24, 27, 30, and $33 \mathrm{~mm})$. Oversizing of $10-30 \%$ was accepted to obtain an optimal stable positioning. Prior to release from the delivery catheter, correct position within the LAA, stability testing and no flow residual flow were assessed. 


\section{Informed Consent and Ethical Considerations}

All patients signed the informed consent form according to the standards of the institution, which follows national and international standards ${ }^{25,26}$. The study was approved by the Research Ethics Committee of the institution.

\section{Post-Ablation Follow-Up}

The patients remained on average one day in the intensive care unit with hospital discharge on the next day, after evaluation of the vascular punctures, chest X-ray and electrocardiogram. Patients received a prescription of sucralfate $2 \mathrm{~g} /$ day associated with pantoprazole $40 \mathrm{mg}$ twice daily for four weeks after the procedure. The reintroduction of the prior antiarrhythmic and anticoagulant drugs was in the same day, after the ablation. For the eight patients with prior severe bleeding with NOAC, we used a dose of $2.5 \mathrm{mg}$ of apixaban twice daily initially for 30 days after the procedure, and in the next 60 days clopidogrel $75 \mathrm{mg} /$ day. The other five patients who had experienced a prior ischemic stroke or had left atrial thrombus despite of NOAC used a course of 60 days of $150 \mathrm{mg}$ of dabigatran twice daily and clopidogrel for the next four months.

Antiarrhythmics were maintained for 90 days and were suspended at this time. After discharge, the evaluations for the rhythm management were at seven and 30 days with a clinical questionnaire, evaluation of the punctures and electrocardiogram in the two visits. They were also evaluated at three, nine and 12 months with electrocardiogram and 24 hours Holter monitoring in the 6-and 12-month follow-up. Up to now, the protocol for the Watchman device assessment was angiotomography at 6-month follow-up for those patients that completed it.

\section{Statistical Analysis}

All tests were performed using BioStat statistical software (AnalystSoft, Walnut, CA, United States). Continuous variables were expressed as mean \pm standard deviation, or as median and interquartile range (IQR).P-value was considered significant if $<0.05$. Continuous variables were compared using the Student's t-test between the two groups. We also used the Fisher exact test and $\chi^{2}$ test.

\section{RESULTS}

The first patient submitted to this combined approach was in 2018 April and the last one in October 2020. The mean follow-up in these group of patients was 14 months, from three to 33, and the recurrence rate of any atrial arrhythmias was observed in three (23.08\%) patients. There were no major periprocedural complications up to 30 days; one patient presented after procedure a pseudoaneurysm of the femoral artery, repaired by thrombin injection in the next day. After this period, we had two (15.38\%) deaths: one related to complications due to chronic renal failure and one after an acute pulmonary edema.

In the 11 patients who completed this analysis, three (27.27\%) had recurrence of atrial tachyarrhythmias, one showed AF with no response to amiodarone and two (one in the 3-month blanking period) showed an atrial tachycardia with a good response to amiodarone recovering the sinus rhythm. At the moment of this analysis, in the 11 patients, we had 10 (90.91\%) in sinus rhythm, nine without antiarrhythmic medications and one with amiodarone, and one (9.09\%) patient in AF.

The mean left atrial time was $79 \pm 18$ minutes, mean total procedure time of $96 \pm 11$ minutes, mean radiofrequency time was $1,875 \pm 221$ seconds, and mean X-ray time of $18 \pm 10$ minutes (Table 3 ).

At six months, we performed atrial and left atrial appendage angiotomography (LACT) in nine patients that achieved this period of the follow-up. The LACT showed successful complete sealing of the LAA evaluated in seven (77.78\%) patients (Fig. 3), and in the other two (22.22\%) patients with a leak of less than $2 \mathrm{~mm}$ in both cases (Fig. 4). There was no device thrombus related or dislodgement of the prothesis. No cardioembolic or bleeding events occurred during the entire follow-up. 
Table 3. Study results.

\begin{tabular}{lc}
\hline Combined procedure results & Patients \\
\hline Sinus rhythm & $10(90.91 \%)$ \\
Complications < 30 days & $1(7.69 \%)-$ minor \\
Complications > 30 days & $79 \pm 18$ minutes \\
Mean left atrial time & $96 \pm 11$ minutes \\
Mean total procedure time & $1,875 \pm 221$ seconds \\
Mean radiofrequency time & $18 \pm 10$ minutes \\
Mean X-ray time & $2(22.22 \%)($ leak $<2$ mm) \\
6-month Watchman leak (9 patients) & $7(53.85 \%)$ \\
Moderate/severe renal dysfunction & $5(38.46 \%)$ \\
Left ventricular dysfunction & $4(30.77 \%)$ \\
Prior ischemic strokes & $4(30.77 \%)$ \\
Diabetes mellitus & \\
\hline
\end{tabular}

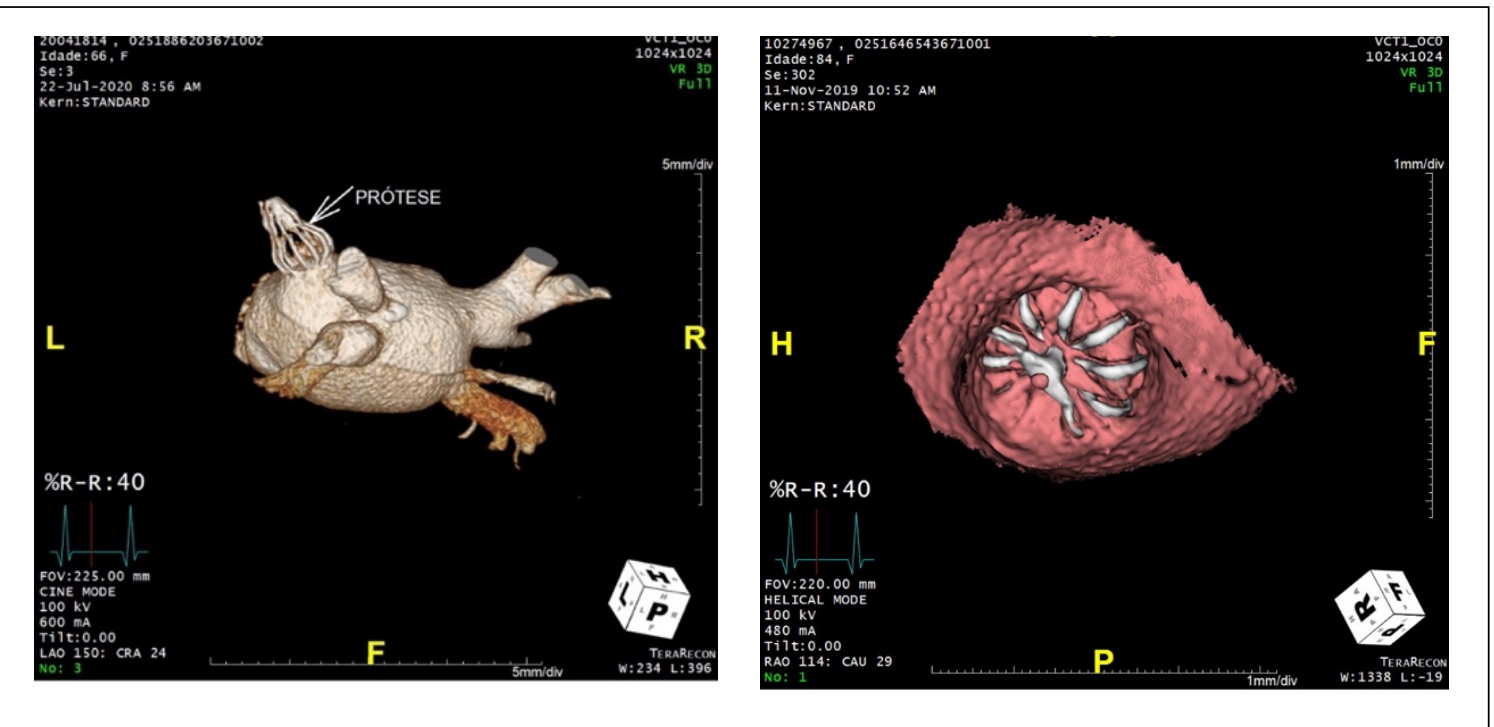

Figure 3. Six months control angiotomography showing complete sealing of the left atrial appendage with no leak or device related thrombus.

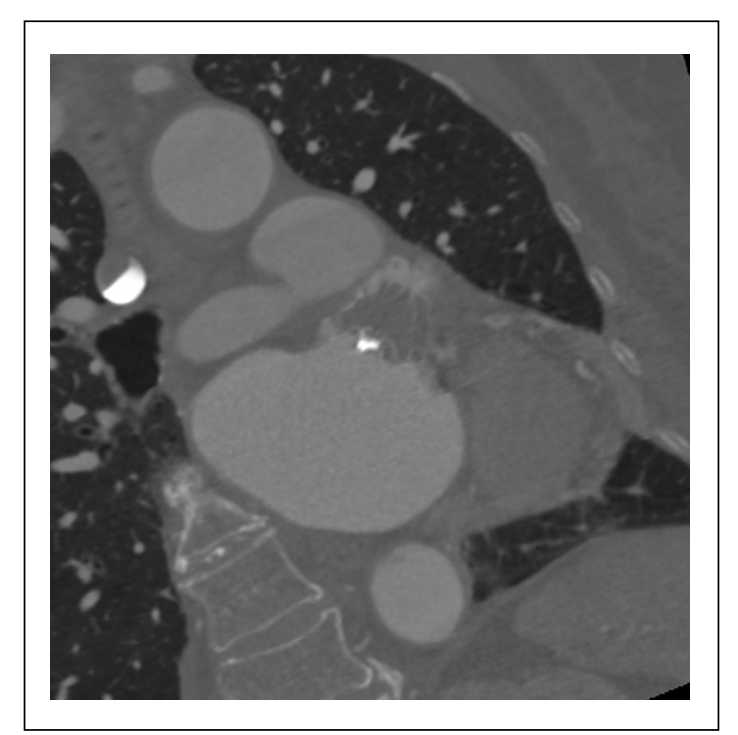

Figure 4. Six months angiotomography control with a mild leak $(<2 \mathrm{~mm})$ and a minor filling of the left atrial appendage. 


\section{DISCUSSION}

Our study, despite being a very small-sized observational one, provides a real-world procedural and middle-term outcome of a combined AF ablation and LAAC procedure, and from our knowledge it is the first one that used the HPSD ablation technique. The results show that such a combined procedure is thoroughly feasible with procedure times of $100 \mathrm{~min}$ and fluoroscopy time of less than $20 \mathrm{~min}$. The procedures show:

- High rates of procedural success;

- Very low rates of complications during procedure;

- Greatly reduced stroke and bleeding rates compared to the expected rates calculated by $\mathrm{CHA}_{2} \mathrm{DS}_{2}-\mathrm{VASc}$ and HASBLED score, respectively;

- AF recurrence in half of the patients.

The data support and strengthen the previously published single-center experiences that CA and LAAC can be combined successfully and safely in one-single procedure p. $^{5-9}$.

The observed procedural success rate compares very favorably with previously reported implant success rates of 91\% in PROTECT-AF, 95\% in PREVAIL, and 98.5\% in EWOLUTION ${ }^{4,8,27}$. Recently, combined procedural data on CA and LAAC of the EWOLUTION and WASP studies were published by Phillips et al. ${ }^{12}$, that showed reduction in complete sealing during follow-up, which was higher for combined procedures than for Watchman LAAC by itself. It has been suggested that post-ablation edema formation may result in an underestimation of the true LAA diameter and consequently undersizing the Watchman implant. However, a substudy of the PROTECT-AF trial on Watchman LAAC alone demonstrated a similar residual peri-device flow in up to $32 \%$ of patients at 12 months of follow-up. Retrospective analysis showed no association between such minimal peri-device flow and the risk of thromboembolism ${ }^{28}$. However, the event rate in PROTECT-AF was low, and clinical consequences of minimal peri-device flow require further investigation.

Overall, minor complication rates up to 30 days were $7.69 \%$, including the one patient with right femoral artery pseudoaneurysm. The serious adverse event rate, that includes pericardial effusion, intracoronary air embolus and stroke, was not observed in the first 30 days after the combined approach. In the previously mentioned studies, the most patients underwent a single LAAC procedure while their complication rates were higher than in our population that underwent combined CA and LAAC, despite our sicker patients when we compared the $\mathrm{CHADS}_{2} \mathrm{VASC}_{2}$ score of the studies.

Left atrial appendage closure has been shown superior to warfarin in terms of stroke prevention and bleeding in largescaled randomized clinical trials4. In this very small sample-sized study, we did not see any stroke or major bleeding in patients after procedure. Even the rate of AF recurrence was very low in our study combining with our previous publications using the HPSD technique ${ }^{29,30}$. The LAA, among other non-pulmonary vein triggers, has been reported to be an effective adjuvant ablation target ${ }^{31}$. However, it needs to be noticed that there is currently no evidence that Watchman LAAC contributes to electrical isolation of the LAA.

In a large series of 349 patients, Wintgens et al. ${ }^{13}$ described that the combined approach for the treatment of atrial fibrillation is feasible, safe, and successful. With this large prospective and multicenter trial, we conducted our single center, small-size observational trial, that also showed that this combined technique is safe, successful, and feasible, but in our series we saw a marked reduction in time of the procedure, success rates of sinus rhythm maintenance and total sealing of the left atrial appendage with also no case of cardioembolic events in comparison to the mentioned study.

\section{Study Limitations and Future Directions}

The first and most important limitation of the study is the small sample. Since the LAAC is not a certified procedure by the federal regulation agency in our country, it became an exceptional approach for patients that have any kind of limitation for the use of $\mathrm{OAC}$ or for those who even in the use of these drugs experienced a new cardioembolic event. The follow-up was also too short. Even with the limitations of the study, the data showed that the combined approach in this niche of patients is feasible and can be a new direction to be followed soon. 


\section{CONCLUSION}

In this study, using the high-power technique for a short period of time in combination with the LAAC, we saw a low rate of procedure complications and a high rate of sinus rhythm and left atrial appendage complete sealing leading to no stroke during follow up.

\section{ACKNOWLEDGMENTS}

We thank the Cardiac Imaging Cardiologists Ariane Binoti Pacheco Leal and José Guilherme Cazelli for the support in the tomography imaging support. For their effort in data collection and patience, we appreciate the dedication of Christiane Amaral and Vanessa Rodrigues, from the administration staff, and Edevaldo da Silva, Rafael Zeni and Anderson Barcelos, from the biomedical team.

\section{FUNDING}

Not applicable.

\section{DATA AVAILABILITY STATEMENT}

The datasets generated during and/or analyzed during the current study are available from the corresponding author on reasonable request.

\section{REFERENCES}

1. Kirchhof P, Benussi S, Kotecha D, Ahlsson A, Atar D, Casadei B, et al. 2016 ESC guidelines for the management of atrial fibrillation developed in collaboration with EACTS. Europace. 2016;18(11):1609-78. https://doi.org/10.1093/europace/euw295

2. Nyong J, Amit G, Adler AJ, Owolabi OO, Perel P, Prieto-Merino D, et al. Efficacy and safety of ablation for people with non-paroxysmal atrial fibrillation. Cochrane Database Syst Rev. 2016;11(11):CD012088. https://doi.org/10.1002/14651858.cd012088.pub2

3. Lip GYH, Andreotti F, Fauchier L, Huber K, Hylek E, Knight E, et al. Bleeding risk assessment and management in atrial fibrillation patients: a position document from the European Heart Rhythm Association, endorsed by the European Society of Cardiology Working Group on Thrombosis. Europace. 2011;13(5):723-46. https://doi.org/10.1093/europace/eur126

4. Reddy VY, Sievert H, Halperin J, Doshi SK, Buchbinder M, Neuzil P, et al. Percutaneous left atrial appendage closure vs warfarin for atrial fibrillation. JAMA. 2014;312(19):1988-98. https://doi.org/10.1001/jama.2014.15192

5. Holmes DR Jr., Kar S, Price MJ, Whisenant B, Sievert H, Doshi SK, et al. Prospective randomized evaluation of the Watchman Left Atrial Appendage Closure device in patients with atrial fibrillation versus long-term warfarin therapy: the PREVAIL trial. J Am Coll Cardiol. 2014;64(1):1-12. https://doi.org/10.1016/j.jacc.2014.04.029

6. Reddy VY, Doshi SK, Kar S, Gibson DN, Price MJ, Huber K, et al. 5-Year Outcomes After Left Atrial Appendage Closure: From the PREVAIL and PROTECT AF Trials. J Am Coll Cardiol. 2017;70(24):2964-75. https://doi.org/10.1016/j.jacc.2017.10.021

7. Phillips KP, Walker DT, Humphries JA. Combined catheter ablation for atrial fibrillation and Watchman VR left atrial appendage occlusion procedures: five-year experience. J Arrhythm. 2016;32(2):119-26. https://doi.org/10.1016/j.joa.2015.11.001

8. Swaans MJ, Alipour A, Rensing BJ, Post MC, Boersma LVA. Catheter ablation in combination with left atrial appendage closure for atrial fibrillation. J Vis Exp. 2013;(72):3818. https://doi.org/10.3791\%2F3818 
9. Alipour A, Swaans MJ, Van Dijk VF, Balt JC, Post MC, Bosschaert MAR, et al. Ablation for atrial fibrillation combined with left atrial appendage closure. JACC Clin Electrophysiol. 2015;1(6):486-95. https://doi.org/10.1016/j.jacep.2015.07.009

10. Calvo N, Salterain N, Arguedas H, Macias A, Esteban A, García de Yébenes M, et al. Combined catheter ablation and left atrial appendage closure as a hybrid procedure for the treatment of atrial fibrillation. Europace. 2015;17(10):1533-40. https://doi. org/10.1093/europace/euv070

11. Fassini G, Conti S, Moltrasio M, Maltagliati A, Tundo F, Riva S, et al. Concomitant cryoballoon ablation and percutaneous closure of left atrial appendage in patients with atrial fibrillation. Europace. 2016;18(11):1705-10. Concomitant cryoballoon ablation and percutaneous closure of left atrial appendage in patients with atrial fibrillation. Europace

12. Phillips KP, Pokushalov E, Romanov A, Artemenko S, Folkeringa RJ, Szili-Torok T, et al. Combining Watchman left atrial appendage closure and catheter ablation for atrial fibrillation: multicentre registry results of feasibility and safety during implant and 30 days follow-up. Europace. 2018;20(6):949-55. https://doi.org/10.1093/europace/eux183

13. Wintgens L, Romanov A, Phillips K, Ballesteros G, Swaans M, Folkeringa R, et al. Combined atrial fibrillation ablation and left atrial appendage closure: long-term follow-up from a large multicentre registry. Europace. 2018;20(11):1783-9. https://doi.org/10.1093/ europace/euy025

14. Oral H, Knight BP, Tada H, Ozaydin M, Chugh A, Hassan S, et al. Pulmonary vein isolation for paroxysmal and persistent atrial fibrillation. Circulation. 2002;105(9):1077-81. https://doi.org/10.1161/hc0902.104712

15. Cappato R, Calkins H, Chen SA, Davies W, lesaka Y, Kalman J, et al. Updated worldwide survey on the methods, efficacy, and safety of catheter ablation for human atrial fibrillation. Circ Arrhythm Electrophysiol. 2010;3(1):32-8. https://doi.org/10.1161/ circep.109.859116

16. McLellan AJA, Kumar S, Smith C, Morton JB, Kalman JM, Kistler PM. The role of adenosine following pulmonary vein isolation in patients undergoing catheter ablation for atrial fibrillation: a systematic review. J Cardiovasc Electrophysiol. 2013;24(7):742-51. https://doi.org/10.1111/jce.12121

17. Macle L, Khairy P, Weerasooriya R, Novak P, Verma A, Willems S, et al. Adenosine-guided pulmonary vein isolation for the treatment of paroxysmal atrial fibrillation: an international, multicentre, randomised superiority trial. Lancet. 2015;386(9994):672-9. https:// doi.org/10.1016/s0140-6736(15)60026-5

18. Kuck KH, Reddy VY, Schmidt B, Natale A, Neuzil P, Saoudi N, et al. A novel radiofrequency ablation catheter using contact force sensing: Toccata study. Heart Rhythm. 2012;9(1):18-23. https://doi.org/10.1016/j.hrthm.2011.08.021

19. Reddy VY, Shah D, Kautzner J, Schmidt B, Saoudi N, Herrera C, et al. The relationship between contact force and clinical outcome during radiofrequency catheter ablation of atrial fibrillation in the TOCCATA study. Heart Rhythm. 2012;9(11):1789-95. https://doi. org/10.1016/j.hrthm.2012.07.016

20. Yokokawa M, Bhandari AK, Tada H, Suzuki A, Kawamura M, Ho I, et al. Comparison of the Point-by-Point versus Catheter Dragging Technique for Curative Radiofrequency Ablation of Atrial Fibrillation. Pacing Clin Electrophysiol. 2011;34(1):15-22. https://doi. $\operatorname{org} / 10.1111 / j .1540-8159.2010 .02944 . x$

21. Neuzil P, Reddy VY, Kautzner J, Petru J, Wichterle D, Shah D, et al. Electrical Reconnection After Pulmonary Vein Isolation Is Contingent on Contact Force During Initial Treatment Results from the EFFICAS I Study. Circ Arrhythm Electrophysiol. 2013;6(2):327-33. https:// doi.org/10.1161/circep.113.000374

22. Kautzner J, Peichl P. Contact Force Assessment in Catheter Ablation of Atrial Fibrillation. J Atr Fibrillation. 2014;6(6):1047. https://doi. org/10.4022\%2Fjafib.1047

23. Kautzner J, Neuzil P, Peichl P, et al. Contact force, FTI and lesion continuity are critical to improve durable PV isolation: EFFICAS 2 results. Heart Rhythm. 2012;9:S28.

24. Leite LR, Santos SN, Maia H, Henz BD, Giuseppin F, Oliveira A, et al. Luminal Esophageal Temperature Monitoring with a Deflectable Esophageal Temperature Probe and Intracardiac Echocardiography May Reduce Esophageal Injury During Atrial Fibrillation Ablation Procedures. Results of a Pilot Study, Circ Arrhythm Electrophysiol. 2011;4(2):149-56. https://doi.org/10.1161/circep.110.960328

25. Brasil. Ministry of Health. National Agency of Sanitary Surveillance. Resolution of the Board of Directors DRC No. 9, of February 20, 2015. Brazil; 2015.

26. Rickham PP. Human experimentation. Code of ethics of the World medical association. Declaration of Helsinki. Br Med J. 1964;2(5402):177. https://doi.org/10.1136\%2Fbmj.2.5402.177

27. Viles-Gonzalez JF, Kar S, Douglas P, Dukkipati S, Feldman T, Horton R, et al. The clinical impact of incomplete left atrial appendage closure with the Watchman Device in patients with atrial fibrillation: a PROTECT AF(Percutaneous Closure of the Left Atrial Appendage 
Versus Warfarin Therapy for Prevention of Stroke in Patients with Atrial Fibrillation) substudy. J Am Coll Cardiol. 2012;59(10):923-9. https://doi.org/10.1016/j.jacc.2011.11.028

28. Holmes Jr. DR, Kar S, Price MJ, Whisenant B, Sievert H, Doshi SK, et al. Prospective randomized evaluation of the Watchman Left Atrial Appendage Closure device in patients with atrial fibrillation versus long-term warfarin therapy: the PREVAIL trial. J Am Coll Cardiol. 2014;64(1):1-12. https://doi.org/10.1016/j.jacc.2014.04.029

29. Vassalo F, Meigre LL, Serpa E, Lovatto C, Cunha C, Carloni H, et al. Better Outcomes in High-Power Short-Duration Compared to Low-Power Long-Duration Atrial Fibrillation Ablation in One-Year Follow-Up. 2020;2(6):OAJBS.ID.000218. https://doi.org/10.38125/ OAJBS.000218

30. Vassallo F, Meigre LL, Serpa E, Lovatto C, Cunha C, Carloni H, et al. The First-Pass Isolation Effect in High-Power Short-Duration Compared to Low-Power Long-Duration Atrial Fibrillation Ablation: A Predictor of Success. J. Cardiac Arrythmias. 2020;33(3):161-9. https://doi.org/10.24207/jca.v33i3.3406

31. Weerasooriya R, Khairy P, Litalien J, Macle L, Hocini M, Sacher F, et al. Catheter ablation for atrial fibrillation: are results maintained at 5 years of follow-up? J Am Coll Cardiol. 2011;57(2):160-6. https://doi.org/10.1016/j.jacc.2010.05.061 